\title{
Development of Real Time Heart Rate Monitoring \& Alert System with GSM \& GPS Techniques
}

\author{
Sudhindra $\mathrm{F}^{1}$, Annarao S. $\mathrm{J}^{2}$, Vani R.M $\mathbf{M}^{3}$, Hunagund P.V \\ Technical Officer-I, U.S.I.C, Gulbarga University, Kalaburagi, Karnataka, India ${ }^{1}$ \\ HOD of Electronics, HKE's Women's Polytechnic, Kalaburagi, Karnataka, India ${ }^{2}$ \\ Prof\& Head, U.S.I.C, Gulbarga University, Kalaburgi, Karnataka, India ${ }^{3}$
}

Prof. \& Chairman Dept. of P. G. Studies and Research in Applied Electronics, Gulbarga University,

Kalaburagi, Karnataka, India ${ }^{4}$

\begin{abstract}
Various wireless communications is often essential in the field of tele-medicine, home security and industrial security etc. Now a day's people of all age groups are suffering from two common medical ailments that are Blood Pressure and Blood Sugar. Monitoring of these parameters or Bio-vitals has always been a challenging task to the research community. There are many parameters which always require constant monitoring like Blood pressure, Heart rate or pulse, ECG, Body temperature etc. The blood pressure is a very critical bio-vital as it is directly related to heart. Hence, in-turn measurement of heart rate is highly essential. Timely remedial medical measures/assistance can save the heart patient from heart failure. Advanced technologies are available to monitor the heart rate. The heat rate/pulse rate can be measured at any point on the body where artery's pulsation pressure is transformed to the body surface by pressing it with index \& middle finger. This traditional/conventional method is being used by physicians. The other method is using of digital devices. Latest development in microcontrollers, wireless communications techniques, GSM \& GPS technologies, high sensitive wearable sensors have led the monitoring of heart rate more accurate, thus helps the patients to move around without restriction or otherwise patients are confined to the hospital environment. This paper describes a simple 51 architecture based low cost real time heart rate/pulse rate monitoring system that uses digital device OMRON NIBP unit. For clinical trials, the system was taken to the hospital and tested on different age \& weight people. Then these results are compared with readings taken by Doctor using traditional methods. The developed system also uses GSM \& GPS technologies. The GSM is for bio-vital signal information transformation through SMS and GPS is for location awareness. The developed system is aimed at aged or elderly people, as the movement of these people is restricted because of age factor \&other health related issues. Combination of various technologies in a single module fulfils the needs of delivering critical information to concerned people.
\end{abstract}

Keywords: Non-Invasive Blood Pressure, Heart rate, bits per minute, GSM and GPS.

\section{INTRODUCTION}

Heart diseases are major worldwide life-style diseases. In Now, we get many cases where people in the 25-35 age olden days, issues such as age, gender, family history were group are diagnosed with heart disease' said Dr Ajay mainly responsible for these diseases. But last few decades, Chaurasia, head of cardiology department, BYL Nair heart disease has crossed all the boundaries and now Hospital in a study.

controllable risk factors like diet, physical inactivity and Heart rate is the number of beats per unit of time, typically stress main causes of the heart disease. Our country will expressed as beats per minute (bpm). It can vary as the soon bear the high burden of heart disease. In India, the body's need to absorb oxygen and excrete carbon dioxide population of more than 1.27 billion, about 45 million changes, such as during physical exercise, sleep, illness, or people are suffering from heart dieses. In a latest estimates, as a result of ingesting drugs: Amphetamines which is a India will have the highest number of cases of heart related stimulant of central nervous system increases the heart diseases in the world,' says Dr Nikhil Kumar, Director, rate. The depressants or sedative components of central Cardiology, Fortis Memorial Research Institute, nervous system decrease the heart rate. There is a Gurgaon. It is estimated to account for $35.9 \%$ deaths by the minimum heart rate and maximum heart rate. For normal year 2030. Heart disease is more prevalent in the younger resting position heart rates range from 60-100 bpm in generation: Heart disease has escalated among the younger adults. These minimum \& maximum values of heart rate generation with a significant risk in both males and some time may go up and down due to various medical females. 'More and more number of young Indians are reasons. Medical Science has given two separate words for suffering from coronary artery disease, owing to their poor these maximum and minimum values of heart rate. lifestyle, and if this continues the future looks even more Bradycardia is defined as the heart rate below 60 bpm in dangerous,' says Dr Kumar. 'Five years ago, we hardly resting. Tachycardia is defined as the heart rate above 100 saw young patients with heart problems.

bpm while in rest. 
Classification of Heart Rate: The following table shows, wireless sensors to collect the bio-signal information from the classification of heart rate in different age group.

\begin{tabular}{|l|l|}
\hline Table 1 Heart Beat Range \\
\hline Age Group & $\begin{array}{l}\text { Heart Beat } \\
\text { Range }\end{array}$ \\
\hline Below 1 year & 110 to $160 \mathrm{bpm}$ \\
\hline 1 to 2 years & 100 to $150 \mathrm{bpm}$ \\
\hline 2 to 5 years & 90 to $140 \mathrm{bpm}$ \\
\hline 5 to 12 years & 80 to $120 \mathrm{bpm}$ \\
\hline $\begin{array}{l}\text { Above } 12 \\
\text { years }\end{array}$ & 60 to $100 \mathrm{bpm}$ \\
\hline
\end{tabular}

multiple patient's body. A coordinator node receives these data and sends to a base station. Any abnormalities can alert the doctor through SMS/E-mail [8]. Rifat Shahriyar et.al designed intelligent mobile health monitoring system by using various technologies such as wearable body sensor network, patient's personal home server and an intelligent medical server for monitoring various physiological parameters [9]. Janny S. Choy et.al studied a fully implantable telemetry system to measure hemodynamic in swine heart failure with the help of a wirelessly positioned radio frequency link [10]. Amna Abdullah et.al has developed a real time wireless health monitoring

Heart Rate/Pulse Rate Measurement: There are two ways, It is measured by finding the pulse of the heart. This pulse rate can be found at any point on the body where the artery's pulsation pressure is transformed to the body surface by pressuring it with the index and middle fingers; often it is compressed against an underlying structure like bone. This is traditional method of measurement of heart rate by physician. The radial artery is the easiest way to use to check the heart rate. However, in emergency situations the most reliable arteries to measure heart rate are carotid artery. The other method is to use digital devices like NIBP unit, pulse oximeter etc.

This paper proposes a system that performs non-invasive method of measurement of the heart rate based on oscillometric method by using OMRON make digital NIBP model HEM-7111 which has a wearable cuff sensor. The system is able to evaluate the heart rate. The proposed system is rigorously tested in the hospital for clinical trials. Finally the results are compared.

\section{RELATED WORK}

The literature survey shows that, the application of latest technologies for measurement of heart rate such as wireless devices/sensors etc for remote monitoring. M.V.M Figueredo et.al suggests the implementation of telemedicine system using mobile telephony in which wireless sensors collects the data and sends through RS232 to a server with internet facility [1] P.S Pandian et.al reports wireless sensor network and its application to wearable physiological monitoring system using personal area network [2]. Maxime Labat et.al implemented wearable blood pressure sensor for collecting the vital data and used electrocardiogram \& Photopletysmograph [3]. Piyush V. Savaliya et.al says the use of short distance communication method such as Bluetooth for measurement of bio-vitals based on FPGA approach [4]. M. Vinaykumar et.al adapts the use of ARM controller with GSM technique for collection \& transmission of physiological parameters wirelessly on a cell phone [5]. Sriram K Vasudevan et.al checks the adaptability of Zigbee communication method which collects \& transmits the bio signals to a computer, so that doctor can monitor the patient within the hospital premises [6]. Priya.M et.al attempted to develop PIC based wireless intensive care unit monitoring system using the Zig-bee protocol. Wireless sensors collect the data and Zigbee transmits these data to a PC through RS232 so that doctor can monitor patient's vital information on his PC remotely [7]. Media Aminian et.al also suggests the use of front end program for recording physiological parameters [11]. S. Elango et.al presents an in-home healthcare system for monitoring health related parameters using National Instruments WSN module with Lab-VIEW front end program which sends the medical data to WSN gateway through wireless media [12]. Mohamed Fezari et.al reports development of heart rate monitoring system based on a single chip microcontroller, which analysis the heart beats rate signals in real time, also claims advantageous of portability over tape based recording system and he also mentions zero crossing algorithm to compute heart rate [13]. Ping Wang et.al writes on implementation of physiological parameter monitoring system for in-patient which has two systems one is patient physical state data acquisition system and the other is ZigBee communication technique [14]. S. Ahmad et.al makes a note on development of an integrated Blood pressure \& ECG device for multi-parameter physiologic monitoring and ECG signals are harvested to analyze other parameters [15]. Xiao Hu et.al suggests the use of wireless body area sensor network based on Zig-Bee technology for telemedicine monitoring system [16]. Physiological parameters can not be varied on the living subject (human being) instantly, considering this point authors have suggested a GSM \& GPS enabled simulated blood pressure monitoring system in which the values of systolic \& diastolic pressures varied with the help of electronic circuit $[17,18]$. Recently the author of this paper experimented real time ambulatory blood pressure monitoring system based on oscillo-metric method, on live subjects and verifies the results with the results taken by traditional methods [19]. This paper proposes design and development of a simple low cost 51 architecture microcontroller based embedded system that monitors the heart rate. The system also uses GSM \& GPS network to transmit the vital information \& location awareness. It also compares the values obtained from the developed system under clinical trials with the values taken by doctor with traditional methods.

\section{III.THE SYSTEM OUTLINE}

Here, we have proposed a simple 51 architecture family of microcontroller based heart rate monitoring system. The system uses Non-invasive method for heart rate measurement \& Omron make NIBP model HEM-7111 is used. The developed system is also called Ambulatory because at specific interval of time $(2 \mathrm{~min})$ it takes readings 
for heart as this method is very much essential for cardiac patients wherein every specified interval of time it is necessary to monitor the heart rate. The system uses GSM architecture/network \& its ability for mobile communication to transmit the bio-vital signal information to an authorized person's cell phone. The system also has GPS connectivity for identification of location, by taking Longitudinal \& Latitudinal values of the geographical location of the GPS receiver and sends information in the form of SMS. The system has ability to respond to SMS messages sent by the caretaker/doctor, verifies the authenticity and then sends a reply to SMS with which one can know the status of physiological parameter of concern person.

\section{IV.METHODS AND MATERIALS}

Fig.1 shows the functional block diagram of the proposed systems. The hardware is built on 51-architecture. The components are OMRON make NIBP model HEM-7111, LCD display unit, GPS receiver, GSM modem, ADC, physiological parameter setting knobs etc. Many of the components are common for a normal embedded system. We will discuss all the components in brief in the following sections

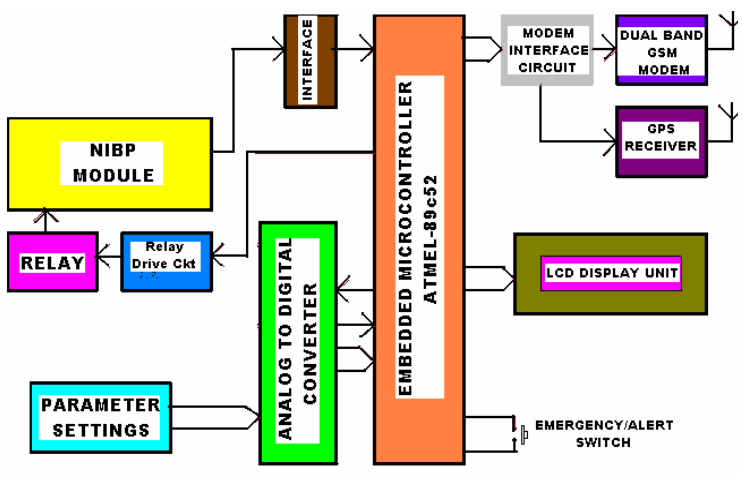

Fig.1. Functional Block Diagrams of two systems

1. 89c52- Microcontroller.

2. Dual Band GSM Modem

3. GPS Receiver

4. OMRON NIBP-HEM-7111

5. Relay \& Driver circuit

6. Analog to Digital Converter (ADC)

7. LCD Display unit.

8. Physiological parameter settings Knobs

9. Emergency Switches

1. Embedded microcontroller: Atmel's 89C52 microcontroller is used for this work and it will carryout all controlling activities of the system by executing a program stored into its program memory. It is an 8-bit microcontroller with $8-\mathrm{k}$ bytes of internal flash program memory, 256-byte data memory and 4-I/O ports. It has a full duplex serial UART and internal timer/counter. It is a very good choice for compact embedded system design with low cost.

2. Dual band GSM modem: GSM stands for Global Standards for Mobile Communication Systems. This MODEM is a wireless unit which can send \& receive data through the GSM network. It requires a SIM card and connectivity to the GSM network. It has built in TCP/IP stack. The GSM MODEM communicates with the embedded microcontroller system with the help of AT commands. It works on two frequencies i.e. $900 \mathrm{MHz}$ and $1800 \mathrm{MHz}$ for up-linking and down-linking. Hence it is called as Dual band GSM MODEM. This MODEM is designed to work on RS232 standard, hence, while connecting to microcontroller, a RS232 to TTL level converter is essential.

3. GPS receiver: It is a network of satellites that constantly transmit coded information, due to which it is possible to accurately identify locations on earth by measuring distance from the satellites. GPS Receiver is available as interface modules from various manufacturers. This type of GPS is capable of sending information through a simple serial link. The GPS used in this system will receive the coordinates needed from the GPS satellites. It will send the information to the microcontroller. Due to its compact size and low power consumption, it can be embedded into many portable devices. It has the ability to refresh its data once every second and therefore will be continuously updating the coordinate values for the microcontroller as the person changes location.

Subscriber Identity Module: Subscriber Identity Module popularly known as a SIM card is a key factor of GSM. It is a detachable smart card containing the user's subscription information and phonebook.

Short Message Service (SMS): Short Message Service is most famous among mobile cell phone users as a cheap and convenient method of communicating. Because the use of SMS technique is a cheap, convenient and flexible way of conveying data, many of wireless embedded system uses SMS communication method for remote monitoring and controlling.

4. OMRON NIBP module (HEM7111): - The Blood Pressure is measured using OMRON NIBP module. It has a pneumatic pressure pump and an external inflating rubber cuff and a strain gauge based pressure measurement sensor. After receiving command from the microcontroller, this module slowly inflates the cuff and senses the pressure in the cuff. After the pressure goes just above the systolic pressure, it records this value and after that it starts to deflate the cuff. After the pressure goes just bellow the diastolic pressure, it records this value also. In the mean time it also counts the heart rate by sensing the pulsations in the pressure. The microcontroller sends commands and extracts the values of systolic pressure and diastolic pressure from this module through the serial RS-232 port link as shown in fig.2

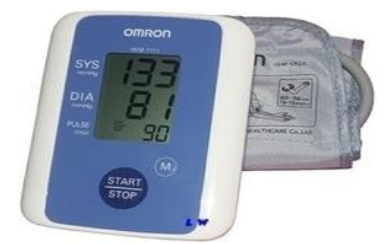

Fig.2. Image of OMRON NIBP Module HEM-7111

5. Relay \& Relay driver circuit: It is used to turn ON the NIBP unit. A time loop is created within the program so as 
to ON \& OFF the NIBP unit within specified time interval says for example $2 \mathrm{~min}$. For every $2 \mathrm{~min}$ the NIBP unit automatically turns ON \& OFF and takes fresh readings. Repeatedly taking of readings within specified intervals are highly essential for risky cardiac patients.

6. Analog to digital converter (ADC): It is used to convert the analog signal into a binary number. An ADC converts the input signal into a proportional binary value, by taking some time. When it finishes conversion and is ready with the digital data, it indicates with an end of conversion signal. It is an 8-bit, successive approximation type ADC 0809.

7. LCD display Unit: It is a Liquid Crystal Display module for displaying various messages according to the situation locally. A 2-line, 16 character type LCD module with backlit facility is used. The microcontroller sends the signals to LCD module through its ports.

8. Physiological parameter settings Knobs: An additional facility available to the doctor to set the heart rate of a particular patient, as the doctor himself knows these vales very accurately if he monitors ones or twice. Any abnormalities in these parameters from the set values will be reported immediately through SMS.

9. Emergency Switches: It is a simple push button switch. In case of emergency i.e medical disorder, by simply pressing this emergency switch, the system becomes active, takes the readings and sends the message to doctor with fresh bio-vital information.

\section{V.SOFTWARE IMPLEMENTATION}

The developed systems is a dedicated embedded system based on 51 architecture, software is written in assembly language \& stored in the memory of the controller. Before giving power supply, the NIBP module must be connected to the patient. When power is switched ON the system comes to ON condition from RESET position, then the program is executed and controller reads the information \& displays it on LCD display and also sends SMS to doctor.

\section{EXPERIMENTAL RESULTS \& DISCUSSIONS}

The designed \& developed system was taken to the hospital for clinical trials. Initially the Casualty Medical Officer (CMO) of the hospital took the heart/pulse rate (bpm) readings for 10 different age patients with their traditional method of manual counting of pulse on wrist. These readings were recorded. Then developed instrument was connected to the same 10 patients and obtained the readings. The results are shown in table 1.

Finally these readings were compared. Then we have observed that, there is only 5 to 10 units variations in the readings which is normally admissible. The photograph of the experimental setup is shown in fig. 3 \& the SMS message on to the doctor's cell phone is shown in fig. 4 . The photo-snap of the experimental set up while it was on clinical trials in the hospital is shown in fig.5. The system has expressed its functionality with GSM network for heart rate monitoring and notification in case of medical emergencies.
TABLE 1. COMPARISION OF HEART RATE READINGS TAKEN BY DOCTOR AND READINGS OBTAINED FROM THE DEVELOPED INSTRUMENT

\begin{tabular}{|l|l|l|l|l|}
\hline $\begin{array}{l}\text { Sl. } \\
\text { No }\end{array}$ & $\begin{array}{l}\text { Subject } \\
\text { Identity }\end{array}$ & $\begin{array}{l}\text { Weight } \\
\text { In } \\
\mathbf{K g}\end{array}$ & $\begin{array}{l}\text { Heart rate } \\
\text { (pulse) in bpm } \\
\text { Taken by } \\
\text { Doctor by } \\
\text { manually } \\
\text { counting the } \\
\text { pulses. }\end{array}$ & $\begin{array}{l}\text { Heart rate } \\
\text { (pulse) in } \\
\text { bpm taken by } \\
\text { the developed } \\
\text { instrument. }\end{array}$ \\
\hline 1. & Patient-1 & 68 & 88 & 93 \\
\hline 2. & Patient-2 & 47 & 102 & 96 \\
\hline 3. & Patient-3 & 55 & 78 & 73 \\
\hline 4. & Patient-4 & 72 & 80 & 85 \\
\hline 5. & Patient-5 & 67 & 72 & 68 \\
\hline 6. & Patient-6 & 75 & 79 & 82 \\
\hline 7. & Patient-7 & 40 & 84 & 81 \\
\hline 8. & Patient-8 & 48 & 98 & 95 \\
\hline 9. & Patient-9 & 78 & 88 & 83 \\
\hline 10. & Patient-10 & 65 & -3 & 76 \\
\hline
\end{tabular}

The location awareness is obtained through GPS technique. The system gets the geographical locations from GPS receiver to calculate the latitude and longitude of the place/location and prepares a concise SMS and sends the information through the GSM modem to the mobile phone of the doctors as in fig. 4 From the above discussions it is clear that the system is automatic, wireless, portable and practically suitable for patients.

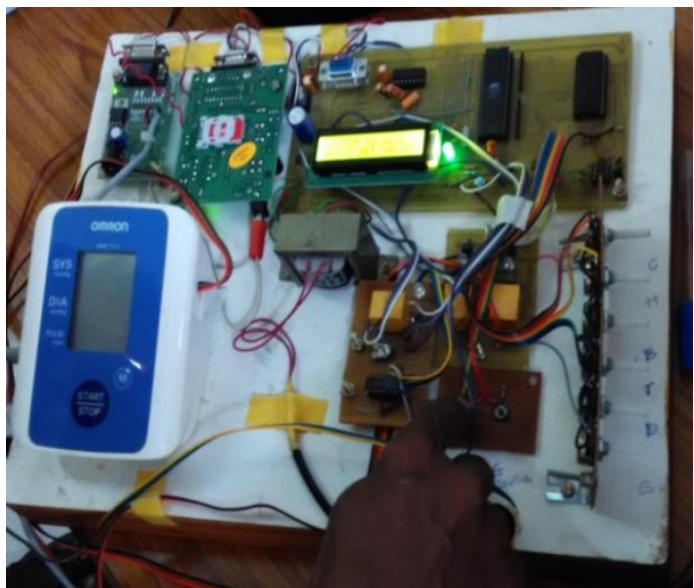

Fig.3. Photo snap of the experimental setup

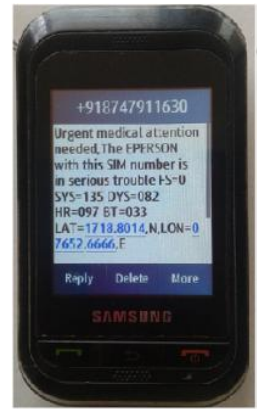

Fig.4. Photograph of Cell phone with SMS sent by the system

The details of this SMS are as follows:

- Heart Rate in bpm (HR) = 097

The GPS locations are:

- $\quad$ LAT=1718.8014.N (Latitude North)

- $\quad \mathrm{LON}=07652.6666 . \mathrm{E}$ (Longitude East) 


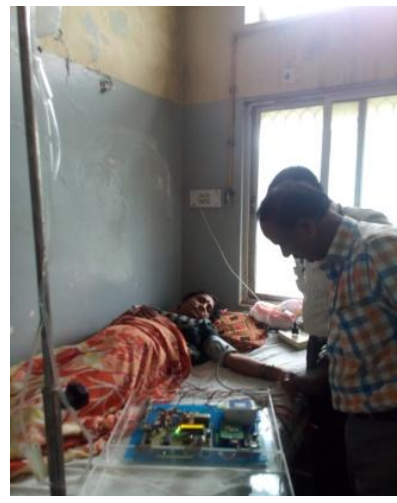

Fig.5. Photograph of the instrument while on clinical trial.

\section{CONCLUSION}

The development \& implementation of the real time heart rate monitoring system is to sense, send, display and store the physiological parameter such as heart rate. The system is simple, low cost and portable. The final objective of the work is to reduce the cost of hospitalization \& assistance and to increase patient's quality of life. The system has functioned satisfactorily and can be used by elderly people or people suffering from various medical ailments \& which improves medical care quality of adult or elderly people.

\section{REFERENCES}

[1] M.V.M Figueredo and J.S. Dias Mobile Telemedicine System for Home Care and Patient Monitoring Proceeding of 26th IEEE EMBS International conference on Engineering in Medicine and Biology Society, San Francisco, CA, USA, PP 3387-3390, Sept2004.

[2] P.S. Pandian., K.P. Safeer., Pragati Gupta., D.T. Shankuntala., B.S. Sundersheshu and V.C. Padaki Wireless Sensor Network for Wearable Physiological Monitoring International Journal of Networks, vol-3, issue-5, pp 21-29, May-2008.

[3] Maxime Labat., Guillaume Lopez., Masaki Shuzo, Ichiro Yamada., Yasushi Imai and Shintaro Yanagimoto Wearable Blood Pressure Monitoring System-Case study of multiplatform applications for medical use Proceeding of the International conference on Health Informatics, Rome, Italy, pp 156-163, Jan-2012.

[4] Piyush V. Savaliya., Sunil B. Somani and Virendra V. Shete "A Bluetooth Tele Health, Household Security and Industry Safety Realization by Android Smartphone" International journal of Advanced Research in Computer and Communication Engineering, Vlo-4, issue-6, PP 382-385, June-2015.

[5] M. Vinaykumar and M. Sagar An ARM and GSM Based Global Embedded Patient Monitoring System International Journal of Science and Research, Vol-3, Issue-10, PP 1700-1702, Oct-2014.

[6] Shriram K Vasudevan., Sivaraman R., Subashri V and Murali N Design and Development of an Embedded System for Monitoring the Health Status of a Patient International Journal of Intelligent Systems and Applications, Vol-5, issue-4, pp 64-71, March-2013.

[7] Priya. M., Mathubala.R.S., Anitha. $M$ and Vanitha $M$ Embedded Based Wireless ICU Monitoring System International Journal of Advances in Engineering \& Technology, vol-6, issue-5, PP 20842092, Nov-2013.

[8] Media Aminian and Hamid Reza Naji A Hospital Healthcare Monitoring System Using Wireless Sensor Networks Journal of Health and Medical Informatics, vol-4, issue-2, PP 1-6, Feb-2013.

[9] Rifat Shashriyar., Md. Faizul Bari., Gourab Kundu., Sheikh Iqbal Ahmed and Md. Mostofa Akbar Intelligent Mobile Health Monitoring System (IMHMS) International Journal of Control and Automation, Vol-2, issue-3, PP 13-28, Sept-2009.

[10] Jenny S. Choy., Zhen-Du Zhang., Koullis Pitsillides., Margo Sosa and Ghassan S. Kassab Longitudinal Hemodynamic Measurement in Swine Heart Failure Using a Fully Implantable Telemetry System Journal of PLOS-one, Vol-9, Issue-8, PP 1-12, August2014
[11] Amna Abdullah., Asma Ismael., Aisha Rashid., Ali Abou-ElNour and Md. Tarique Real Time Wireless Heath Monitoring Application using Mobile Devices International Journal of Computer Networks \& Communication, Vol-7, Issue-3, PP 13-29, May2015.

[12] S. Elango., N. Mathivanan and K. Arun Venkatesh Design and Development of wireless Sensor Network for In-Home Healthcare Application Using LabVIEW Journal of the Instrument Society of India, Vol-41, No-4, PP 233-236, Dec-2011.

[13] Mohamed Fezari., Mounir Bousbia-Salah and Mouldi Bedda Microcontroller Based Heart Rate Monitor The International Arab Journal of Information Technology, Vol-5, No-4, PP 153-157, Oct2008.

[14] Ping Wang The Real-time monitoring system for in-patient based on Zigbee Proceedings of Second International Symposium on Intelligent Information Technology Application (IITA), PP 587590, Shanghai, Dec-2008.

[15] S. Ahmed., S. Chen., K. Soueidan., I. Batkin., M. Bolic., H. Dajani and V. Groza A Prototype of an Integrated Blood Pressure and electrocardiogram Device for Multi-parameter Physiologic Monitoring Proceedings of IEEE International Conference on Instrumentation and Measurement Technology (I2MTC), PP 12441249, Austin. TX, May-2010.

[16] Xiao Hu., Jiaqing Wang., Qun Yu., Waixi Liu and Jian Qin A wireless Sensor Network based on Zigbee for Telemedicine Monitoring System Proceedings of IEEE International Conference on Bioinformatics and Biomedical Engineering (ICBBE), PP 13671370, Shanghai, May-2008.

[17] Sudhindra.F., Annarao.S.J., Vani.R.M and P.V.Hunagund A GSM Enabled Real Time Simulated Heart Rate Monitoring \& Control System International Journal of Research in Engineering and Technology (IJRET), Vol-3, Special Issue-3, PP 6-10, May-2014.

[18] Sudhindra.F., Annarao.S.J., Vani.R.M and P.V.Hunagund A GSM \& GPS Enabled Real Time Simulated Heart Rate Monitoring \& Control System Proceedings of $102^{\text {nd }}$ Indian Science Congress 2014-15, Mumbai University, Mumbai, Maharastra, PP 63, Jan2015.

[19] Sudhindra.F., Annarao.S.J., Vani.R.M and P.V.Hunagund A Low Cost Real Time Ambulatory Blood Pressure Monitoring \& Alert System with GSM \& GPS Indian Journal of Scientific Research (IJSR), Vol -12, issue-1, PP 180-186, Oct-2015.

\section{BIOGRAPHIES}

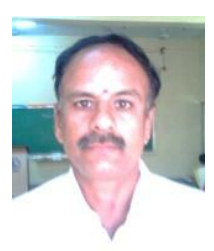

Sudhindra F. Received his B.E (E\&CE) from Gulbarga University, Gulbarga and Master's degree from KSOU, Mysore. He is working as Technical Officer-I in University Science Instrumentation Centre, Gulbarga University, Gulbarga since 1995. He has completed his M.Phil from Gulbarga University, Gulbarga. He has attended many seminars, workshops and conferences. His areas of interest are digital electronics, Embedded Controllers and Wireless communication. He has serviced and repaired more than 500 laboratory instruments.

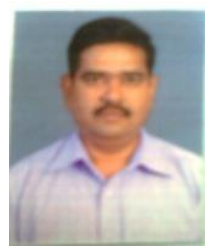

Annarao.S.J. received his B.Tech (E\&CE) from Guru Ghasidas University, Bilaspur Chattisgarh and pursuing Master's degree from KSOU, Mysore. He is working as Head of Department in Electronics and Communication Engineering Department of HKE Society's women's polytechnic, Gulbarga. He has attended many seminars, workshops and conferences. His areas of interest are embedded systems, Biomedical, RFID, GSM, GPS, Wireless communication and Computers. He has guided more than 500 live projects for diploma, BE and M.Tech students. 
Vani R. M. received her B.E. in Electrical and Electronics from the B.I.ET., Davanagere and M.Tech in Industrial Electronics from S.J.C.E., Mysore, Karnataka. She has received her Ph.D in Applied Electronics from Gulbarga University, Gulbarga, India, in year 2005. She is working as Reader \& Head, University Science Instrumentation Center, Gulbarga University, Gulbarga, since 1995. She has more than 85 research publications in national and international reputed journals/Conference proceedings. she presented the research papers in National/ International conferences in India and abroad. She has conducted several courses, workshops for the benefits of faculties and field engineers. Her areas of interest are microwave antennas, PC based instrumentation, embedded controllers and Wireless communication. She has one UGC major research project to her credit

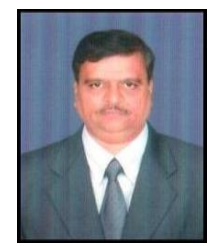

P. V. Hunagund, received his M.Sc and $\mathrm{Ph} . \mathrm{D}$ from the Dept. of Applied electronics, Gulbarga University, Gulbarga, in the year 1982 and 1992 respectively. $\mathrm{He}$ is working as professor and chairman of Applied Electronics department, Gulbarga University, Gulbarga. He has more than 100 research publications in national and international reputed journals, more than 150 research publications in international symposium/Conferences. He has presented the research papers in National/International conferences in India and abroad. He has guided many Ph.D and M.Phil students. He has three major research projects at his credit. He has worked as a committee member in various selection committees for selection of Associate Professor and Professor in different Universities. 